\title{
Submandibular Lymphadenitis
}

National Cancer Institute

\section{Source}

National Cancer Institute. Submandibular Lymphadenitis. NCI Thesaurus. Code C27016.

Inflammation of the submandibular lymph nodes. 